ARAŞTIRMA MAKALESİ

\author{
Muammer Yılmaz ${ }^{1}$ \\ Filiz Bolu ${ }^{2}$ \\ Atilla Senih Mayda ${ }^{2}$ \\ Bayram Poyraz ${ }^{3}$
}

${ }^{1}$ Düzce Toplum Sağlığg Merkezi

Merkez/Düzce

${ }^{2}$ Düzce Üniversitesi Tıp Fakültesi

Halk Sağlığı Anabilim Dalı, Konuralp/Düzce

${ }^{3}$ Düzce Üniversitesi Merkez

Araştırma Laboratuarı, DÜBİT,

Düzce

Yazışma Adresi:

Dr. Muammer Yllmaz

Düzce Toplum Sağlığ Merkezi

Merkez/Düzce

Tel: 05055446365

E-mail: zerkesa@gmail.com

1. Ulusal Su ve Sağlık Kongresi'nde poster bildiri olarak sunulmuştur.

Geliş Tarihi: 10.02.2017

Kabul Tarihi: 01.03.2017

DOI: $10.18521 / \mathrm{ktd} .291267$

Konuralp Tip Dergisi

e-ISSN1309-3878

konuralptipdergi@duzce.edu.tr

konuralptipdergisi@gmail.com

www.konuralptipdergi.duzce.edu.tr

\section{Düzce'de Satılan Şişe Suları İle Musluk Sularının Ağır Metal Düzeylerinin İncelenmesi}

\section{ÖZET}

Amaç: Bu çalışmada şişelenmiş kaynak suları ile Düzce şebeke suyunun ağır metal içeriği açısından karşılaştırılması amaçlanmıştır.

Yöntem: Musluk suyunu analiz etmek için belirlenen 14 ayrı noktadan aynı tarihte numune alınmıştır. Ticari doğal kaynak suyu numuneleri $500 \mathrm{ml}$ pet şişelerde satı̧̧a sunulan 10 farklı markadan alınan örneklerdir. Su örneklerindeki ağır metal değerleri; Inductively Coupled Plasma-Mass Spectrometer (ICP-MS) cihazı ile ölçülmüsştür. Sonuçlar ABD Çevre Koruma Ajansı (EPA), Dünya Sağlık Örgütü (DSÖ) ve T.C. Sağlık Bakanlığı tarafından önerilen kriterlere göre değerlendirilmiştir.

Bulgular: Alınan musluk suyu ve ticari su numunelerinde ağır metal düzeyleri DSÖ, EPA ve T.C. Sağlık Bakanlığı'nın önerdiği limit değerlerden düşük bulunmuştur. Ticari su ağır metal düzeyi ortalaması ile musluk suyu örneklerinin ağır metal düzeyi ortalaması karşılaştırıldığında bor (B), alüminyum ( $\mathrm{Al})$, krom $(\mathrm{Cr})$, mangan $(\mathrm{Mn})$, demir $(\mathrm{Fe})$, nikel $(\mathrm{Ni})$, arsenik ( $\mathrm{As})$, stronsiyum $(\mathrm{Sr})$, molibden $(\mathrm{Mo})$, kadmiyum $(\mathrm{Cd})$, civa $(\mathrm{Hg})$ ve kurşun $(\mathrm{Pb})$ düzeyleri ticari su numunelerinde musluk sularına göre istatistiksel olarak anlamlı düzeyde düşük bulunmuştur.

Sonuç: Ağır metal düzeyleri açısından musluk suyu ve ticari şişe sularının içilmesinde bir sakınca bulunmadığı görülmektedir.

Anahtar Kelimeler: Ticari Su, Musluk Suyu, Ağır Metal

\section{Investigation of Heavy Metal Levels in Tap Water and Bottled Waters Sold in Düzce}

\section{ABSTRACT}

Objective: The aim of the study is to compare bottled spring water with Düzce tap water in terms of heavy metals content.

Methods: To analyze the tap water samples were taken from 14 different determined locations at the same date. Commercial natural spring water samples were in $500 \mathrm{ml}$ plastic bottles sold 10 examples from different brands. Heavy metal concentrations in water samples were measured by Inductively Coupled Plasma-Mass Spectrometer (ICP-MS). Results were evaluated based on the specified criteria of the US Environmental Protection Agency (EPA), the World Health Organization (WHO) and the Ministry of Health of Turkey.

Results: Heavy metal levels in tap water and commercial water samples were lower than limits set by EPA, WHO and the Ministry of Health of Turkey. Average heavy metal content of the commercial water was found to be statistically significantly lower than average tap water heavy metal level, including boron (B), aluminum (Al), chromium (Cr), manganese $(\mathrm{Mn})$, iron (Fe), nickel (Ni), arsenic (As) strontium (Sr), molybdenum (Mo), cadmium $(\mathrm{Cd})$, mercury $(\mathrm{Hg})$ and lead $(\mathrm{Pb})$.

Conclusion: In terms of heavy metal levels it that is safe to drink tap water and commercial bottled waters.

Keywords: Commercial Water, Tap Water, Heavy Metal 


\section{GíRIŞ}

Temel sağlık hizmetlerinin öneminin tam olarak ortaya konduğu uluslararası bir sağlık sözleşmesi niteliğinde olan Alma-Ata bildirgesinde temiz su sağlanması ve sanitasyon en önemli konulardan biri olmuştur (1). Buna göre sağlıklı ve yeterli suyu topluma ulaştırmak kamunun asli bir görevidir. Yerel yönetimler musluktan temiz, sağlıklı ve güvenilir suyun yeterli miktarda akmasını sağlamalı ve bunu önemli bir vazife olarak görmelidir (2).

Türkiye su kaynakları bakımından dünyanın verimli kullanıldığında yeterli olarak nitelendirilen bir bölgesinde yer almasına rağmen, kentleşme sürecine hazırlıksız yakalanılması, plansız kentleşme nedeniyle alt yapı yetersizlikleri, suyun temininde ve temiz su kaynaklarının korunmasında çeşitli sıkıntılara yol açmıştır. Ormanların yok edilmesi, su havzalarının yerleşime açılması su kaynaklarının kendini yenilemesini engellemektedir. İçme ve kullanma suyu ihtiyacına yönelik sağlıklı çözümlerin yıllarca geliştirilememesi, alt yap1 eksikliklerinin giderilememesi toplumu içme suyu ihtiyacını karşılamak için alternatif çözümlere yöneltmiştir $(3,4)$.

Sadece ülkemizde değil birçok gelişmiş ülkede şişelenmiş su, su ihtiyacını gideren bir içecek olmanın ötesinde sağlıklı yaşamın en önemli parçalarından biri olarak algılanmaktadır. Bugün gelişmekte olan bazı ülkelerde de şişelenmiş su, daha hijyenik olduğu için musluk suyuna alternatif olarak görülmektedir. Nitekim Türkiye'de de ambalajlı su ticareti uzun y1llar hijyen sorununu sürekli olarak gündemde tutan yöntemlerle gelişmiştir (4). Göç, nüfus artışı ve bunların sonucunda yaşanan sağllksız kentleşme, zaman zaman şehir musluk sularının kirli su olarak görülmesi, gelir düzeyinin yükselmesi, tüketim tercihlerinin değişmesi, "daha hijyenik ve sağlıklı" lezzetli ve güvenilir içme suyu talebi sonucunda ülkemizde, özellikle kentleşmiş bölgelerde ambalajlı su tüketimi hızla artmaktadır. Marmara, Ege ve İç Anadolu bölgeleri tüketimin en yoğun olduğu kesimlerdir $(4,5)$.

Ülkemizin doğal kaynak suyu rezervleri açısından dünyanın en zengin üçüncü ülkesi olduğu ifade edilmektedir (4). Kayaç ve akiferler içerisinde toplanan, bir çıkış noktasından sürekli olarak kendiliğinden akan sular doğal kaynak suyu olarak tanımlanır (6).

$\mathrm{Su}$ sektöründeki büyüme devam etmektedir ve AB ülkeleri ile karşılaştırıldığında, Türkiye'de ambalajlı su tüketimi 2014 itibariyle bazı AB ülkelerine yaklaşmış, bazılarını da geçmiştir (4). Hayatın temel maddesi olan su, kaynağından kullanım aşamasına kadar kimyasal ve fiziksel kirlenmelere çok elverişli olması nedeniyle, yaşamı tehdit edebilen birçok hastalığın da kaynağı olabilmektedir (7). Sağlıklı su dengeli mineral dağılımı olan, pestisid kalıntıları ve organik maddeler içermeyen, fiziksel ve kimyasal özellikleri belirli kalite parametrelerine uyan ve insan sağlığını olumsuz yönde etkilemeyen su olarak kabul edilir (8). Su kirliliği fiziksel, kimyasal ve biyolojik olmak üzere 3'e ayrılmaktadır.

Suda meydana gelen kirliliğin büyük bir çoğunluğu kimyasal kirlenme ile meydana gelmektedir. Sanayi atıkları, tarımsal ilaç atıkları, petrol, deterjan atıkları su kimyasında önemli değişiklikler yapmaktadır (9). Ayrıca doğal sular, mineral, cevher ve kayaçlarda etkileşim yoluyla ayrışmalara ve bu şekilde metallerin suya karışmasına sebep olabilirler. Bu nedenle bazen yer altı suları çeşitli toksik metaller içerebilir. İçme suları da bu kaynaklardan temin edildiğinden kimyasal bileşimleri sürekli değişir. Toksik etkiye sahip ağır metalleri içeren suların uzun süreli içme amaçlı olarak tüketilmesi insan sağlığını olumsuz yönde etkileyebilir (10). Sözgelimi içme amacıyla kullanılan sularda $\mathrm{As}, \mathrm{Pb}, \mathrm{Mn}, \mathrm{Cd}, \mathrm{Cu}, \mathrm{Hg} \mathrm{Cr}$ gibi ağır metallerin bulunması ciltte incelme, böbrek hasarı, karaciğer sirozu, sinir sisteminde ileti bozuklukları, gibi sorunlara yol açabilmektedir (11). Bu nedenle suların içilebilir olup olmadığına karar verebilmek açısından çeşitli kuruluşlar metal yoğunluğu bakımından bazı değerleri sınır değer olarak kabul etmiştir $(12,13)$.

Toplumun bir bölümünün, su ihtiyacını sağlıklı olduğuna güvenemediği için musluk suyu yerine ambalajlı sulardan karşıladığı bir gerçektir. Ambalajlanarak tüketime sunulan doğal kaynak suları ve içme sularının bakteri içermemesi kadar ağır metal bulunma durumu ve konsantrasyonu da önem arz etmektedir. Bu çalışmada şişelenmiş kaynak suları ile Düzce şebeke suyunun ağır metal içeriği açısından karşılaştırılması amaçlanmıştır.

\section{MATERYEL VE METOD}

Musluk suyunu analiz etmek için numuneler Düzce il merkezinde belirlenen 14 ayrı lokasyondan 31.10.2014 tarihinde 50 ml'lik polipropilen kaplara alınmış ve kapakları kapatılıp numaralandırılarak Düzce Üniversitesi Merkez Araştırma Laboratuvarına gönderilmiştir.

Laboratuvara gönderilen numunelerin pH'ları uzun süre saklamak adına \%67'lik konsantrasyona sahip supra pure HNO3 (Merck, Germany) ile 2 olarak ayarlanmış ve analiz zamanına kadar $+4{ }^{\circ} \mathrm{C}$ de saklanmıştır. Analizde ICP-MS cihazı olarak Thermo Scientific Element X2 (USA), Ultra saf su cihazı olarak Thermo Scientific TKA smart pure 2(USA), pH metre olarak HANNA HI 2221(Germany) cihazları kullanılmıştır. Kalibrasyon için ana stok ve ara stok olarak hazırlanan standart çözeltiler $1000 \mathrm{mg} / \mathrm{L}$ 'lik konsantrasyona sahip olmakla birlikte ICP-MS cihazı için özel olarak kullanılan trace özelliktedir ve Fluka (Switzerland) markasından temin edilmiştir. Analiz sonuçlarının doğruluğunu kontrol etmek amacıyla Sertifikalı referans içme suyu çözeltisi olarak LGC (UK) firmasından ERM- 
CA011b kod'lu Hard Drinking water UK isimli referans içme suyu çözeltisi kullanılmıştır. Çalışma boyunca kalibrasyon ve standart çözeltileri hazırlamak amaciyla kullanılan ultra saf suyun iletkenlik değeri $0.055 \mu$ S'dir. Analizde Çevre Koruma Örgütü (EPA)‘nın uyguladığı EPA 6020 yöntemi kullanılmıştır.

Ticari doğal kaynak suyu numuneleri kaynağı Sakarya, Bursa, Gölcük, Düzce, Bolu ve Kocaeli olan 10 farklı markadan elde edilmiştir. Bu amaçla $500 \mathrm{ml}$ pet şişelerde satışa sunulan örnekler alınarak polipropilen tüplere doldurulmuş ve laboratuvara gönderilmiştir. Düzce Üniversitesi Bilimsel ve Teknolojik Araştırmalar Uygulama ve Araştırma Merkezi'nde (DÜBİT) bor (B), alüminyum (Al), vanadyum (V), krom (Cr), mangan $(\mathrm{Mn})$, demir $(\mathrm{Fe})$, nikel $(\mathrm{Ni})$, bakır $(\mathrm{Cu})$, arsenik (As), stronsiyum (Sr), kadmiyum (Cd), antimon (Sb), civa $(\mathrm{Hg})$ ve kurşun $(\mathrm{Pb})$ ağır metalleri EPA 6020 yöntemi kullanılarak çalışılmıştır. Su örneklerindeki ağır metal değerleri; Inductively Coupled Plasma-Mass Spectrometer (ICP-MS) cihazı ile ölçülmüştür. Sonuçlar T.C. Sağlık Bakanlığı, DSÖ ve ABD Çevre Koruma Ajansı (EPA) tarafından kabul edilmiş kriterlere göre değerlendirilmiştir $(11,12,14) .19$ Ağustos 2011 tarih ve 28030 Sayılı "Klinik araştırmalar hakkında yönetmelik” gereği çalışma için etik kurul onayı alınmamıştır.
Ístatistiksel Analizler: Verilerin değerlendirilmesinde SPSS 18 istatistik programı kullanılmıştır. Nicel veriler aritmetik ortalama ve standart sapma olarak verilmiştir. Bağımsız gruplarda parametrik test koşulları sağlanmadığı için değişkenlerin karşılaştırılmasında MannWhitney $U$ testi kullanılmıştır. İstatistiksel analizlerde, anlamlılık düzeyi $\mathrm{p}<0.05$ olarak alınmıştır.

\section{BULGULAR}

Tablo 1 ve 2'de ticari şişe suyu ve musluk suyu numunelerinde ölçülen ağır metal konsantrasyonları ile DSÖ, EPA ve Sağlık Bakanlığı İnsani Tüketim Amaçlı Sular Hakkında Yönetmelik'te (7.3.2012) verilen sınır değerler gösterilmiştir. Alınan tüm numunelerde ağır metal düzeyleri DSÖ, EPA ve Sağlık Bakanlığı tarafından önerilen limit değerlerden düşük bulunmuştur.

Tablo 3'de numune alınan 10 ticari su markasının ağır metal düzeyi ortalaması ile Düzce ilinde 14 farklı noktadan alınan musluk suyu örneklerinin ağır metal düzeyi ortalamas1 karşılaştırılmıştır. Bor (B), alüminyum (Al), krom $(\mathrm{Cr})$, mangan $(\mathrm{Mn})$, demir $(\mathrm{Fe})$, nikel $(\mathrm{Ni})$, bakır $(\mathrm{Cu})$, arsenik (As), stronsiyum (Sr), kadmiyum $(\mathrm{Cd})$, civa $(\mathrm{Hg})$ ve kurşun $(\mathrm{Pb})$ ticari su numunelerinde musluk sularına göre istatistiksel olarak anlamlı düzeyde düşük bulunmuştur.

Tablo 1. Ticari su numunelerinde ağır metal düzeyleri $(\mu \mathrm{g} / \mathrm{L})$

\begin{tabular}{|c|c|c|c|c|c|c|c|c|c|c|c|c|c|c|}
\hline Ticari Su & B & Al & $\mathrm{V}$ & $\mathrm{Cr}$ & Mn & $\mathbf{F e}$ & $\mathbf{N i}$ & $\mathbf{C u}$ & As & $\mathrm{Sr}$ & Cd & Sb & $\mathrm{Hg}$ & $\mathbf{P b}$ \\
\hline 1 & 6,51 & ÖL & 0,41 & 0,17 & ÖL & 4,23 & 0,32 & 0,04 & 0,11 & 64,78 & 0,03 & 0,24 & 0,05 & ÖL \\
\hline 2 & 3,43 & ÖL & 2,46 & 0,19 & ÖL & 5,68 & 0,16 & ÖL & 0,21 & 14,45 & 0,01 & 0,13 & 0,03 & ÖL \\
\hline 3 & ÖL & ÖL & 0,23 & 0,08 & 0,11 & 7,12 & 0,21 & 0,02 & 0,20 & 43,54 & 0,02 & 0,13 & 0,03 & ÖL \\
\hline 4 & ÖL & ÖL & 1,30 & 0,22 & ÖL & 4,69 & 0,35 & 0,03 & 0,09 & 17,74 & 0,02 & 0,12 & 0,02 & 0,01 \\
\hline 5 & 9,55 & ÖL & ÖL & ÖL & 0,02 & 1,89 & 0,09 & 0,02 & 0,16 & 7,09 & 0,01 & 0,07 & 0,02 & 0,01 \\
\hline 6 & ÖL & ÖL & 0,08 & 0,11 & 0,04 & 0,75 & 0,08 & 0,01 & 0,25 & 15,68 & ÖL & 0,17 & 0,02 & 0,01 \\
\hline 7 & 6,98 & 0,05 & ÖL & 0,04 & 0,60 & 1,45 & 0,20 & 0,60 & 0,16 & 40,44 & 0,01 & 0,01 & 0,02 & 0,01 \\
\hline 8 & 0,02 & ÖL & ÖL & 0,04 & ÖL & 1,85 & 0,14 & ÖL & 0,49 & 35,37 & 0,01 & 0,18 & 0,01 & 0,01 \\
\hline 9 & ÖL & ÖL & 0,01 & 0,09 & 0,87 & 13,14 & 0,29 & 0,19 & 0,29 & 26,88 & 0,01 & 0,20 & 0,02 & 0,05 \\
\hline 10 & ÖL & ÖL & ÖL & 0,07 & 0,49 & 8,56 & 0,21 & 0,10 & 0,36 & 31,35 & 0,01 & 0,20 & 0,02 & 0,03 \\
\hline DSÖ/EPA $^{\text {a }}$ & - & 200 & 10 & 50 & 500 & - & 70 & 2000 & 10 & 4000 & 3 & 6 & 10 & - \\
\hline $\mathbf{S B}^{\mathbf{b}}$ & 1000 & 200 & - & 50 & 50 & 200 & 20 & - & 10 & - & 5 & - & 1 & 10 \\
\hline
\end{tabular}

a. Dünya Sağlık Örgütü / ABD. Cevre Koruma Ajansı,

b. TC. Sağlık Bakanlığı, ÖL:Ölçüm limitlerinin altında

Tablo 2. Musluk suyu numunelerinde ağır metal düzeyleri $(\mu \mathrm{g} / \mathrm{L} /)$

\begin{tabular}{|c|c|c|c|c|c|c|c|c|c|c|c|c|c|c|}
\hline $\begin{array}{l}\text { Musluk suyu } \\
\text { numunesi }\end{array}$ & B & Al & $\mathbf{V}$ & $\mathrm{Cr}$ & Mn & $\mathrm{Fe}$ & $\mathrm{Ni}$ & $\mathbf{C u}$ & As & $\mathrm{Sr}$ & Cd & Sb & Hg & $\mathbf{P b}$ \\
\hline 1 & 60,98 & 113,3 & 0,741 & 0,739 & 0,414 & 12,38 & 1,819 & 9,61 & 0,367 & 219,7 & 0,046 & 0,142 & 0,607 & 0,1 \\
\hline 2 & 71,16 & 42,59 & 0,386 & 0,591 & 0,497 & 14,46 & 3,416 & 12,25 & 0,515 & 210 & 0,027 & 0,124 & 0,128 & 0,043 \\
\hline 3 & 18,94 & ÖL & 0,844 & 0,62 & 1,388 & 16,34 & 1,581 & 3,46 & 0,475 & 228,2 & 0,043 & 0,171 & 0,107 & 0,526 \\
\hline 4 & 12,23 & 9,779 & 1,014 & 0,659 & 0,189 & 14,29 & 1,836 & 11,87 & 0,74 & 287,3 & 0,043 & 0,045 & 0,074 & 0,215 \\
\hline 5 & 81,78 & ÖL & 0,523 & 0,92 & ÖL & 12,37 & 1,454 & 19,58 & 0,472 & 236,6 & 0,032 & 0,14 & 0,05 & 0,392 \\
\hline 6 & 89,96 & 64,34 & 0,499 & 0,892 & 0,579 & 12,08 & 1,9 & 8,46 & 0,627 & 225 & 0,028 & 0,12 & 0,042 & 0,18 \\
\hline 7 & 81,2 & 5,586 & 0,516 & 0,797 & 1,028 & 11,46 & 1,491 & 11,21 & 0,732 & 199,7 & 0,029 & 0,109 & 0,029 & 0,119 \\
\hline 8 & 56,87 & 11,69 & 0,397 & 0,542 & 0,528 & 36,47 & 0,806 & 10,28 & 0,577 & 131,2 & 0,015 & 0,078 & 0,037 & 0,08 \\
\hline 9 & 67,34 & 72,67 & 0,318 & 0,78 & 0,325 & 26,26 & 1,387 & 36,58 & 0,645 & 150,2 & 0,02 & 0,079 & 0,04 & 0,065 \\
\hline 10 & 99,55 & 17,03 & 1,763 & 0,119 & 0,325 & 31,89 & 1,851 & 12,28 & 0,978 & 49,66 & 0,011 & 0,377 & 0,031 & 0,43 \\
\hline 11 & 91,19 & ÖL & 0,339 & 0,636 & 3,068 & 11,25 & 2,87 & 100,13 & 0,342 & 203,7 & 0,045 & 0,115 & 0,023 & 0,746 \\
\hline 12 & 54,49 & 22,4 & 0,241 & 0,392 & 1,417 & 26,87 & 0,79 & 35,64 & ÖL & 108,4 & 0,022 & 0,075 & 0,02 & 0,156 \\
\hline 13 & 82,17 & 22,95 & 0,313 & 1,465 & 0,498 & 44,69 & 1,622 & 46,7 & 0,525 & 172,2 & 0,029 & 0,109 & 0,017 & 0,125 \\
\hline 14 & 28,35 & 34,88 & 0,062 & 0,167 & 0,037 & 5,23 & 5,431 & 14,58 & 0,785 & 50,95 & 0,008 & 0,047 & 0,019 & 0,019 \\
\hline DSÖ/EPA ${ }^{a}$ & - & 200 & 10 & 50 & 500 & - & 70 & 2000 & 10 & 4000 & 3 & 6 & 10 & - \\
\hline $\mathbf{S B}^{\mathbf{b}}$ & 1000 & 200 & - & 50 & 50 & 200 & 20 & - & 10 & - & 5 & - & 1 & 10 \\
\hline
\end{tabular}

a. Dünya Sağlık Örgütü / ABD. Çevre Koruma Ajansı

b. TC. Sağlık Bakanlığ 
Tablo 3. Ticari sulardaki ağır metal ortalama değerleri ile musluk sularının karşılaştırılması

\begin{tabular}{|c|c|c|c|}
\hline Ağır Metal & $\begin{array}{c}\begin{array}{c}\text { Ticari Su } \\
(\mu \mathrm{g} / \mathrm{L})\end{array} \\
\end{array}$ & $\begin{array}{c}\text { Musluk Suyu } \\
(\mu \mathrm{g} / \mathrm{L})\end{array}$ & p \\
\hline Bor (B) & $2,649 \pm 3,71$ & $64,015 \pm 27,47$ & $<0,001$ \\
\hline Alüminyum (Al) & $0,005 \pm 0,01$ & $29,801 \pm 33,3$ & 0,001 \\
\hline Vanadyum (V) & $0,449 \pm 0,81$ & $0,568 \pm 0,42$ & 0,48 \\
\hline Krom (Cr) & $0,101 \pm 0,71$ & $0,665 \pm 0,33$ & $<0,001$ \\
\hline Mangan (Mn) & $0,213 \pm 0,31$ & $0,735 \pm 0,80$ & 0,031 \\
\hline Demir (Fe) & $4,936 \pm 3,87$ & $19,717 \pm 11,5$ & $<0,001$ \\
\hline Nikel (Ni) & $0,205 \pm 0,09$ & $2,018 \pm 1,20$ & $<0,001$ \\
\hline Bakır (Cu) & $0,010 \pm 0,18$ & $23,75 \pm 25,3$ & $<0,001$ \\
\hline Arsenik (As) & $0,232 \pm 0,12$ & $0,598 \pm 0,17$ & $<0,001$ \\
\hline Stronsiyum (Sr) & $29,732 \pm 17,2$ & $176,629 \pm 70,4$ & $<0,001$ \\
\hline Kadmiyum (Cd) & $0,13 \pm 0,008$ & $0,028 \pm 0,01$ & 0,004 \\
\hline Antimon (Sb) & $0,145 \pm 0,06$ & $0,123 \pm 0,08$ & 0,154 \\
\hline Civa (Hg) & $0,02 \pm 0,01$ & $0,087 \pm 0,15$ & 0,036 \\
\hline Kurşun (Pb) & $0,013 \pm 0,01$ & $0,228 \pm 0,21$ & $<0,001$ \\
\hline
\end{tabular}

\section{TARTIŞMA}

İçme suları içerisinde bulunmaması gereken ya da belirli miktarı geçmemesi gereken ağır metallerin içme ve kullanma sularındaki periyodik ölçüm ve kontrollerinin önemi, metallerin canlı organizmalarındaki olumsuz etkilerinin belirlenmesiyle artmıştır (15). Bu nedenle içme sularında ağır metal düzeylerinin belirlenmesi halk sağlığı açısından önemli ve zorunlu hale gelmiştir. Türkiye'de içme amaçlı olarak tüketilen şişe sularının kalitelerinin ve ağır metal düzeylerinin belirlenmesine yönelik az sayıda araştırma yapılmıştır.

Akdeniz ve İç Anadolu bölgelerinden alınan kaynak suyu numunelerinde yapılan bir araştırmada bazı doğal kaynak suyu örneklerinde bromat, mangan ve arsenik yüksek bulunmuştur (7). Düzce'de yapılan bu çalışmada ise alınan tüm ticari şişe suyu numunelerinde ve tüm musluk suyu numunelerinde ağır metal konsantrasyonları DSÖ ve Sağlık Bakanlığı tarafindan önerilen limit değerlerden düşük bulunmuştur. Özellikle kadmiyum, arsenik, cıva ve kurşun gibi canlılar için eser miktarları bile toksik etki gösterebilen ağır metallerin sınır değerlerin çok altında olması sevindirici bir sonuçtur. Ağır metal düzeyleri açısından musluk suyu ve ticari şişe sularının içilmesinde bir sakınca bulunmadığı görülmektedir.

Düzce'nin içme suyu tek arıtma sisteminden sağlanmaktadır. İçme suyu arıtma tesisinde aritılan su yine tek kaynaktan beslenmektedir. Aşırı kuraklık olması durumunda devreye girmesi için açılmış kuyular arıtma tesisine su temininde rutin olarak kullanılmamaktadır. Çalışmada musluk suyu numuneleri aynı yöntem ile aynı gün içinde alınmış olmasına rağmen ağır metal ölçüm sonuçları birbirinden oldukça farklı olarak bulunmuştur. Örneğin bazı numunelerde ölçülemeyecek düzeyde bulunan Alüminyum, beşinci numunede $5.5 \mu \mathrm{g} / \mathrm{L}$, birinci numunede 113 $\mu \mathrm{g} / \mathrm{L}$ olarak ölçülmüştür. Kurşun, cıva, mangan, bor ve diğer ağır metaller için de aynı durum söz konusudur. İçme suları kaynağında standartlara uygun arıtım işleminin ardından tüketiciye şebeke ile ulaştırılmaya çalışılmaktadır. Ancak tesisatta kullanılan malzeme ya da şebekeyi oluşturan bileşenlerde oluşabilen aksaklıklar, şebeke boruları üzerinde meydana gelebilecek kırılma ve çatlaklar, içme suyunun kalitesini ve ağır metal içeriğini etkileyebilmektedir (16). Bu çalışmada sınır değerlerin altında bulunsa dahi musluk sularında ağır metal konsantrasyonlarının birbirlerinden farklı olmasının nedeninin araştırılması gerekir. $\mathrm{Bu}$ amaçla ana su kaynağı olan derenin, zaman zaman kullanılan kuyuların ve arıtma işleminden geçirildikten sonra şebekeye verilen suyun ağır metal içerikleri incelenebilir. $\mathrm{Bu}$ ağır metal konsantrasyonları şebekenin uç noktaları ile karşılaştırılarak tesisat kaynaklı sorunların hangi ağır metal düzeyini ne kadar etkilediği tespit edilebilir. Çünkü yaşam için temel madde olan su, temiz ve sağlıklı olduğu durumda yararlı olabilir. Sudan kaynaklanan hastalıkların kontrol altında tutulması, musluklarla veya ambalaj ile tüketiciye ulaşıncaya kadar en başta su kaynaklarının kirlenmemesinin sağlanması olmak üzere her aşamada gerekli tedbirlerin alınması ile mümkün olabilir.

Ticari su numuneleri arasında da farklı ağır metal ölçüm sonuçları bulunmuştur. Ancak kayaç ve akiferler içerisinde toplanan, bir çıkış noktasından sürekli olarak kendiliğinden akan sular olarak tanımlanan doğal kaynak sularının farklı kaynaklardan numune alınması sebebiyle ağır metal içeriklerinin farklı olması beklenen bir durumdur (6). 
$\mathrm{Bu}$ çalışmada Düzce'de satılan ticari şişe sularından alınan numunelerin ağır metal düzeyi ortalaması ile Düzce ili musluk suyu numuneleri ağır metal düzeyi ortalaması karşılaştırıldığında Antimon ve vanadyum dışındaki ağır metaller ticari şişe suyu numunelerinde musluk sularına göre istatistiksel olarak anlamlı düzeyde düşük bulunmuştur. Ticari sular ile musluk suyu arasında en büyük fark alüminyumda görülmüştür. Musluk sularında Al düzeyleri limit değerleri aşmamakla birlikte ticari sulara göre oldukça yüksek bulunmuştur. Mısır'da yapılmış benzer bir çalışmada aynı şekilde musluk ve ticari şişe sularında Al sınır değerler içinde ve muslukta daha yüksek bulunmuştur (17). Suda alüminyum doğal ve yapay nedenlerle mevcut olabilir. Alüminyumun sularda doğal olarak bulunuşu asidik suların mineralleri çözmesi ile olurken, yapay olarak bulunma nedeni su arıtımında koagülasyon işlemi için Al tuzlarının kullanımıdır. Düzce Belediyesi içme suyu arıtma tesislerinde özellikle suyun bulanık olarak geldiği zamanlarda $\mathrm{Al}$ koagülan olarak kullanılmaktadır (18). Al'un suya karışmasını engellenmek için Al tuzları yerine kullanılabilecek alternatifler Fe'li ve organik koagülanlardır (19). Yüksek $\mathrm{Al}$ düzeylerinin Alzheimer, Parkinson, amiotrofik lateral sklerozis (ALS) anemi gibi sağlı üzerine ciddi etkileri olabilmektedir (20).

$\mathrm{Bu}$ çalışmada Fe değerleri hem ticari su numunelerinde hem de musluk suyu numunelerinde sınır değerlerin altında bulunmuştur. Poyraz ve arkadaşlarının Marmara Bölgesi'nde içme sularını inceledikleri çalışmada da Fe değerlerinin sınır değerlerin altında olduğu ortaya konmuştur (21). Başka bir çalışmada ise Fe değerleri sınır değerlerin üzerinde bulunmuştur (22). DSÖ tarafindan önerilen sınır değerlerin altındaki miktarlar sağlık için herhangi bir risk oluşturmaz. Ancak suda demir düzeyi 1000-3000 ug/L olduğunda tat ve renk bozukluğu meydana gelir (23).

Kadmiyum düzeyleri bu çalışmada ve Mısır'da yapılmış olan bir çalışmada musluk sularında ticari sulara göre yüksek olmakla birlikte normal sınırlarda bulunmuştur (17). Yapılan diğer bir çalışmada da $\mathrm{Cd}$ sınır değerlerin altında bulunmuştur (21). Galvanize borular veya kadmiyum içerebilen çinko borular suda kadmiyumun kaynağı olabilmektedirler.

Kurşun düzeyleri bu çalışmada ve Mısır'da yapılmış olan çalışmada tüm numunelerde sınır değerlerin altında bulunmuştur (17). Yunanistan'da yapılmış bir çalışmada da tüm ticari su numunelerinde kurşun ve diğer ağır metaller sınır değerlerden düşük bulunmuştur (24). Ancak DSÖ kurşunun kan düzeyinin güvenli olduğu net bir değer belirlenemediğini bildirmiştir (25). Kronik kurşun zehirlenmesi depresyon, konsantrasyon güçlüğü gibi bilişsel bozukluklara, periferik nöropatilere ve kronik interstisyel nefropatiye neden olabilir. Çocuklar kurşunun etkilerine daha duyarlıdır. Çocukların uzun süre az miktarda kurşuna maruz kalmaları fiziksel ve psikolojik gelişim düzensizliği ile psikomotor bozukluklara, öğrenme güçlüklerine ve IQ'da düşmeye neden olmaktadır. Kurşunun kümülatif bir zehir olduğu bildirilmektedir. Kurşunun bulunduğu dokuya bağl1 olarak değişen uzun bir yarılanma ömrü vardır. Kanda 28-36 gün, yumuşak dokuda 40 gün, mineralize dokularda ise 25 ylldan fazla sürede atılmaktadır $(26,27)$. Bu nedenle vücutta biriken toplam kurşun miktarındaki artışın engellenmesi gerekmektedir.

Vanadyum düzeyleri bu çalışmada ve benzer bir çalışmada sınır değerlerin altında bulunmuştur (22). Misır'da yapılmış olan çalışmada ise musluk sularında ticari sulara göre yüksek olmakla birlikte normal sinırlarda bulunmuştur (17). Vanadyumun içme sularında bulunması ile ilgili herhangi bir olumsuz etki bildirilmemiş olup, özellikle meslek hastalığı olarak inhalasyon yoluyla aşırı yüksek dozlarda toksik etkiler oluşturduğu bilinmektedir (28).

Bu çalışmada tüm musluk suyu ve ticari su numunelerinde ağır metal düzeyleri T.C. Sağlık Bakanlığı ve uluslararası kuruluşlar tarafindan verilen sınır değerlerin altında bulunmuştur. $\mathrm{Bu}$ açıdan bakıldığında doğal kaynak suları ile şebeke suyunun ağır metal bakımından benzer değerler taşıdığı düşünülmektedir.

\section{SONUÇ}

Suyu topluma ulaştırmak bir kamu hizmetidir ve suyun musluktan temiz, sağlıklı bir şekilde akması yerel yönetimlerin en önemli vazifesidir. Bu nedenle bireylere temiz ve kaliteli suya ulaşma konusunda sorumluluk bırakılmamalıdır. Bu çalışmada Düzce şehir şebeke suyu ve ticari sulardan toplanan su numunelerinde yapılan analizlerde ağır metal düzeylerinin ilgili kuruluşlar tarafından izin verilen limit değerlerin altında çıkması halk sağlığı açısından olumlu bir durumdur. Analizi yapılan ticari ve musluk sularının ağır metal yoğunluğu bakımından içilebilir nitelikte olduğu sonucuna varılmıştır. Ancak musluk suyu numunelerinde aynı kaynağın uç noktalarından aynı gün içinde alınan örnekler olmasına rağmen ağır metal ölçüm sonuçlarının birbirinden farklı bulunması tesisatla ilgili sorun olduğunu düşündürmektedir. Şehir şebeke suyunu dağıtan tesisatın gözde geçirilerek daha kaliteli suyun sunulması sağlanabilir. 


\section{KAYNAKLAR}

1. Güler Ç, Çobanoğlu Z. Su Kirliliği. 1. Baskı, Ankara: Sağlık Bakanlığı Çevre Sağlığı Temel Kaynak Dizisi- 12, 1994.

2. Tekbaş ÖF, Oğur R. Evsel Su Arıtma Cihazlarına Dikkat. TAF Preventive Medicine Bulletin. 2009;8(2):i-ii.

3. Güler Ç, Vaizoğlu SA. Ekosistemler ve Sağlık. Eds.: Güler Ç, Akın L. İn: Halk sağlı̆ğ Temel Bilgiler 2. Cilt. Ankara: Hacettepe Üniversitesi Yayınları, 2012:574-87.

4. Ambalajlı Su Üreticileri Derneği. Sektör Hakkında- Genel Yapı ve rakamsal Büyüklük. http://www.suder.org.tr/sektor.html (Erişim Tarihi: 10.03.2017).

5. Ayabakan S, Çelik A, Erdoğan E, et al. Damacana su pazar analizi ve dağıtım ağı tasarımı. Endüstri Mühendisliği Dergisi. 2007;18(3):2-12.

6. Pehlivan R. Şişe Sularının Kalitesi ve Tüketicinin Korunması. www.gidahareketi.org/su/sise_sularinin_kalitesi.pdf (Erişim Tarihi10.03.2017).

7. Dönderici ZS, Dönderici A, Başarı F. Kaynak sularının fiziksel ve kimyasal Kaliteleri üzerine bir araştırma. Türk Hijyen ve Deneysel Biyoloji Dergisi. 2010;67(4):167-72.

8. Begun A, Ramaiah M, Harikrishna S, et al. Analysis of Heavy Metals Concentration in Soiland Litchens fromVarious Localities of Hosur Road, Bangalore, India. E-J Chem. 2009;6(1):13-22.

9. Sönmez AY, Hisar O, Karataş M, et al. Sular Bilgisi. Nobel Bilim ve Araştırma Merkezi. Ankara: Nobel Basimevi, 2008:64-201.

10. Gündüz T. Çevre Sorunları. Ankara: Bilge Yayıncılık, 1994:130-3.

11. National Primary Drinking Water 2009. http://water.epa.gov/drink/contaminants/upload/mcl-2.pdf (Erişim Tarihi: 07.12.2014).

12. WHO. Guidelines for drinking-water quality: incorporating first addendum Vol. 1, Recommendations. 3rd ed. Electronic version for the Web, 2006. Available from http://www.who.int/water_sanitation_health/dwq/gdwq0506.pdf (Erişim Tarihi: 10.03.2017).

13. T.C. Sağlık Bakanlığı İnsani tüketim amaçlı sular hakkında yönetmelikte değişiklik yapılmasına dair yönetmelik.7.3.2013 tarihli Resmi Gazete. Sayı 28580.

14. U.S. Environmental Protection Agency (EPA) 2012. Edition of the Drinking Water Standards and Health Advisories EPA 822-S-12-001, Office of Water. Washington, DC.

15. Güler Ç. Su Kalitesi. 1. Baskı, Ankara: Sağlık Bakanlığı Çevre Sağlığı Temel Kaynak Dizisi-43, 1997:55-84.

16. Ling EJ, Benham B, Forrester S. Virginia Household Water Quality Program: Heavy Metals in Household Water. Available from http://www.wellwater.bse.vt.edu/files/HeavyMetals442657_pdf.PDF (Erişim Tarihi: 10.03.2017).

17. Saleh MA, Ewane E, Jones J, et al. Chemical Evaluation of Commercial Bottled Drinking Water from Egypt. J Food Compos Anal. 2001;14:127-152 Available online at http://www.idealibrary.com on doi.10.006/jfca.2000.0858 (Erişim Tarihi: 07.12.2014).

18. Düzce Belediyesi 2007 Mali Y1lı İdare Faaliyet Raporu. Erişim http://www.duzce.bel.tr/upload/tr/dosya/dokumanyonetimi/7/08072010143203-1.pdf (Erişim Tarihi: 07.12.2014).

19. Sulardaki Al konsantrasyonlarının sınırlandırılması. http://www.e-kutuphane.imo.org.tr/pdf/898.pdf (Erişim Tarihi: 07.12.2014).

20. Akman Ö, Atasever $S$, Güçlü $E$, et al. Alüminyum ve İnsan. tip.baskent.edu.tr/egitim/mezuniyetoncesi/calismagrp/.../13.P1.pdf (Erişim Tarihi: 07.12.2014).

21. Poyraz B, Taşpınar F. Analysis, Assesment and Principal Component Analysis of Heavy Metals in Drinking Waters of Industrialized Region of Turkey. Int. J. Environ. Res. 2014; 8(4):1261-1270.

22. Yılmaz M, Kara İH, Poyraz B, et al. Konuralp Beldesinde İçme Sularının Elementer Analizi ve İçerdiği Ağır Metaller: Şebeke Suyu, Doğal Kaynak Suyu ve Zemzem Suyunun Karşılaştırılması. Konuralp Tıp Dergisi 2014;6(3):54-8.

23. WHO. Health Criteria And Other İnformation In: Guidelines For Drinking - Water Quality, Vol.:2, Geneva (1996). Available from http://www.who.int/water_sanitation_health/dwq/2edvol2p2b.pdf?ua=1

24. Karamanis D, Stamoulis K, Ioannides KG. Natural radionuclides and heavy metals in bottled water in Greece. Desalination 213. 2007; 90-97.

25. Exposure to lead: a major public health concern. Public Health and Environment World Health Organization 2010 Available from http:/www.who.int/ipcs/features/lead..pdf?ua=1 (Erişim Tarihi: 10.03.2017).

26. Agency for Toxic Substances and Disease Registry. Case Studies in Environmental Medicine (CSEM): Lead Toxicity Cover Page. Available from www.atsdr.cdc.gov/csem/lead/pbcover_page2.html (Erişim Tarihi: 07.12.2014).

27. Yapıcı G, Can G, Şahin Ü. Çocuklarda Asemptomatik Kurşun Zehirlenmesi. Cerrahpaşa Tıp Derg. 2002;33(3):197-204.

28. Air Quality Guidelines - Second Edition chapter 6.12. Available from http://www.euro.who.int/_data/assets/pdf_file/0016/123082/AQG2ndEd_6_12vanadium.PDF (Erişim Tarihi: 10.03.2017). 